\title{
SEPARATA
}

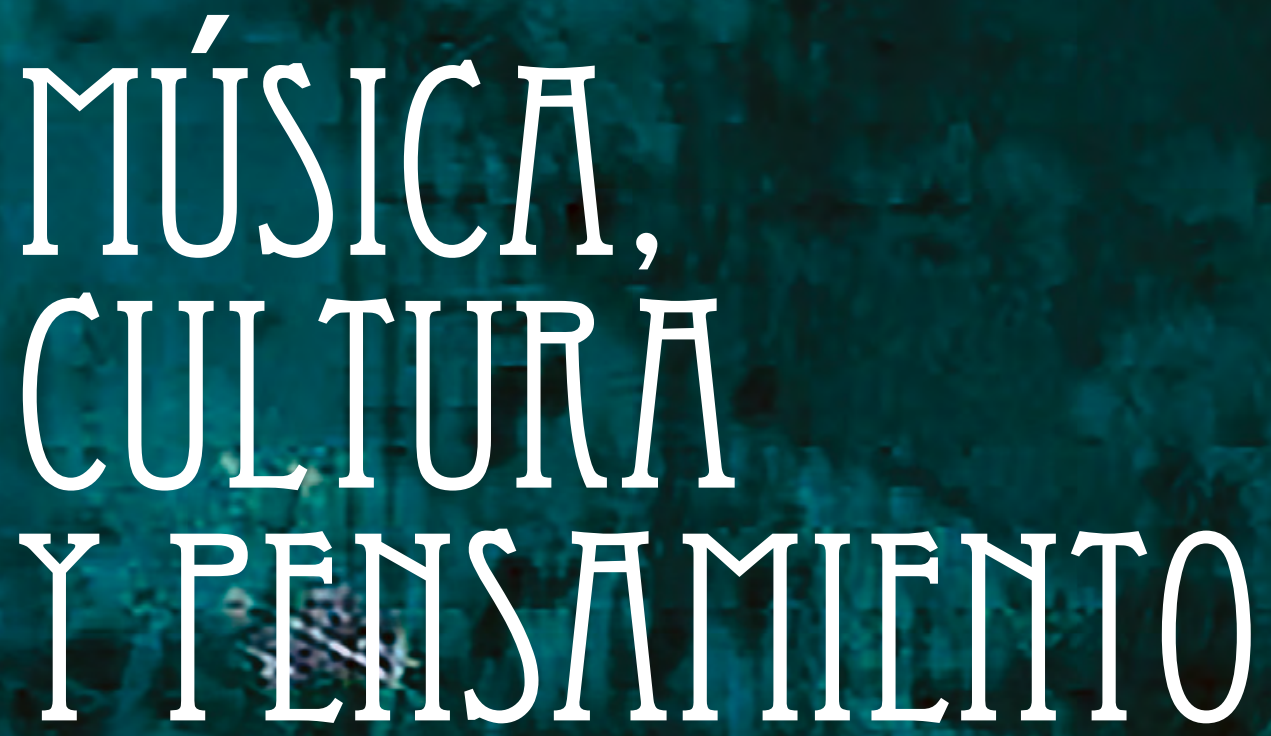

Andrés A. Garzón Charry

Niebla de Chipre

Segundo premio en el primer Concurso Internacional de Composición "Música Jove 2016" - Valencia (España)

A mi maestra Viktoria Gumenaia

FEC

Fondo Editorial Conservatorio del Tolima lbagué

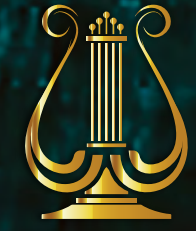

CONSERVATORIO DEL TOLIMA 
Separata Niebla de Chipre

Música, Cultura y Pensamiento, vol. 7, núm. 7 Revista de la Facultad de Educación y Artes.

(C) Fondo Editorial Conservatorio del Tolima. 2018 Conservatorio del Tolima

12 páginas, partitura, $23 \times 30 \mathrm{~cm}$.

ISMN: 979-0-9005303-7-0

Prohibida la reproducción total o parcial de este material sin autorización escrita del Conservatorio del Tolima.
Diseño gráfico editorial, armada electrónica e impresión Proceditor Ltda.

Calle 1C No. 27A - 01, piso 1, Santa Isabel Tel.: 757 9200, proceditor@yahoo.es Bogotá, D. C., Colombia 


\section{Niebla de Chipre}

Segundo premio en el primer Concurso Internacional de Composición "Música Jove 2016” - Valencia (España). a mi maestra Viktoria Gumenaia
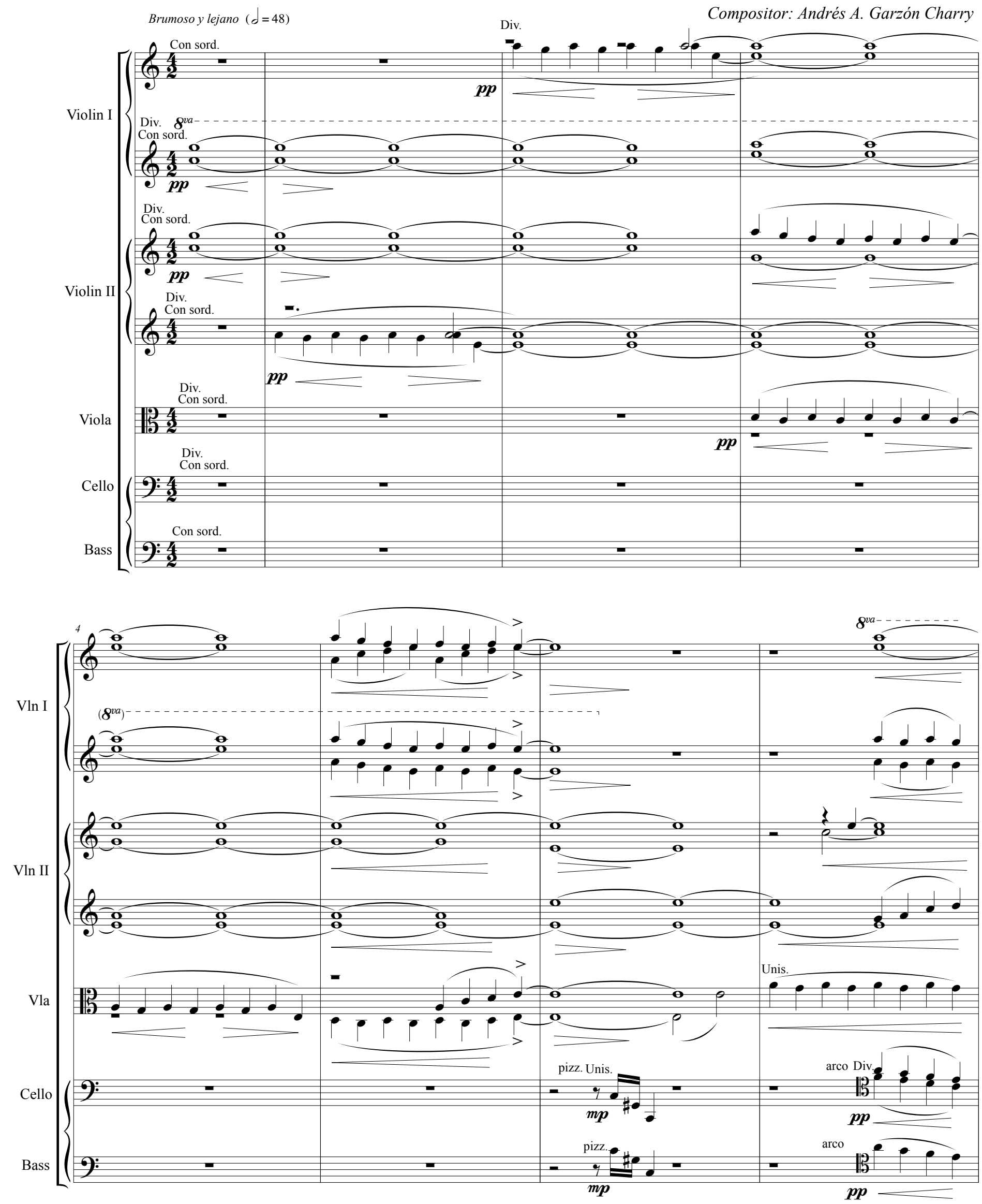

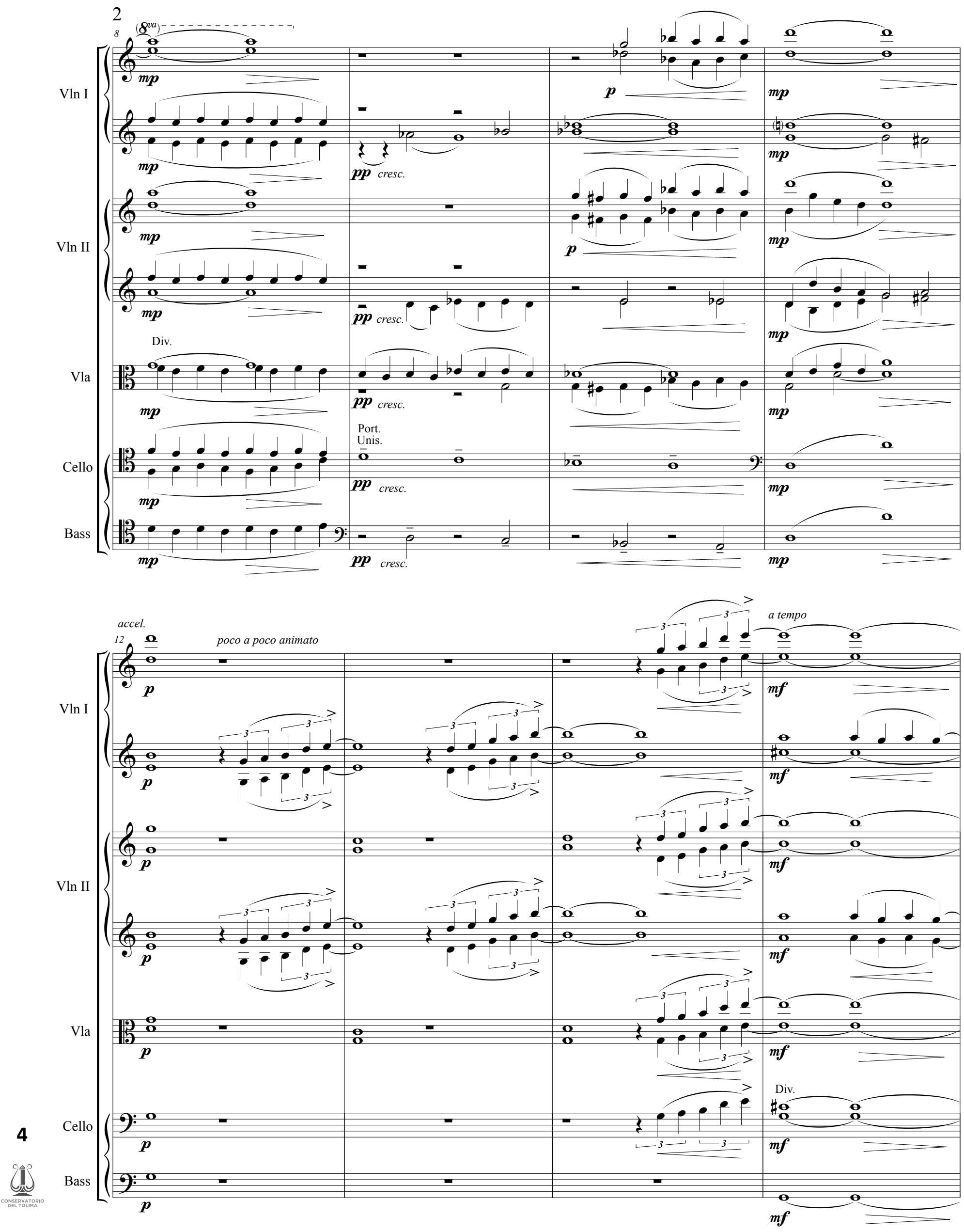

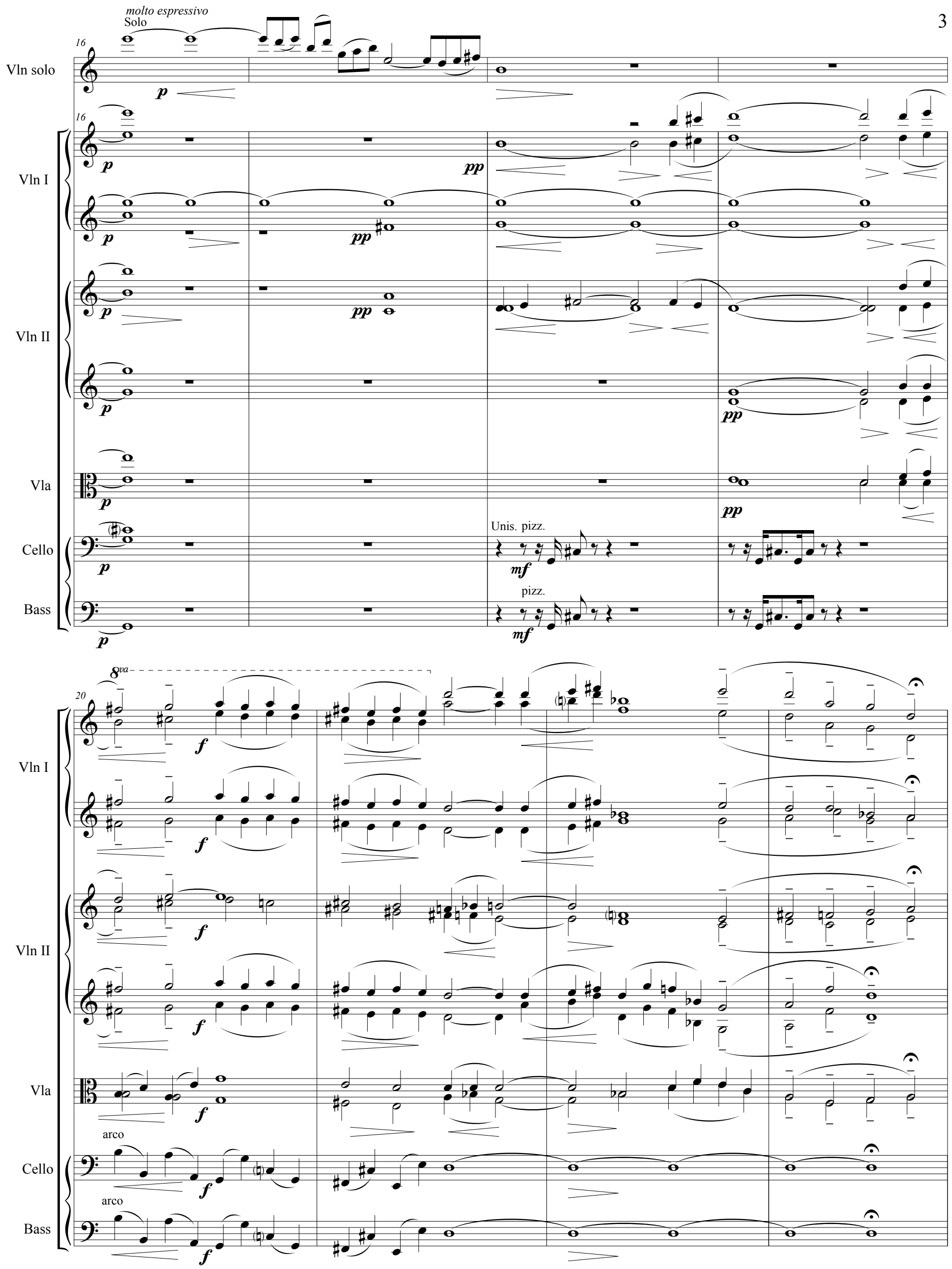

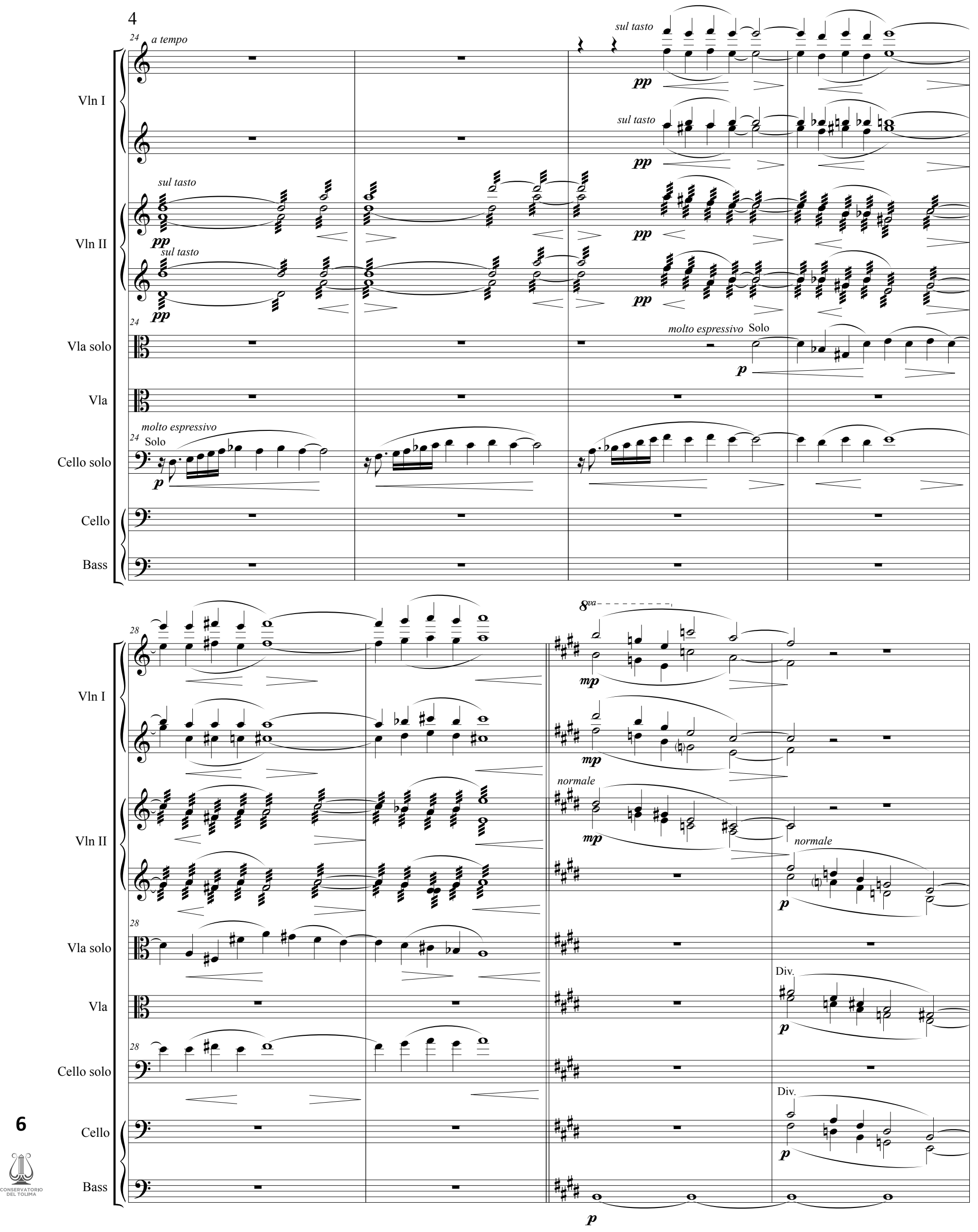

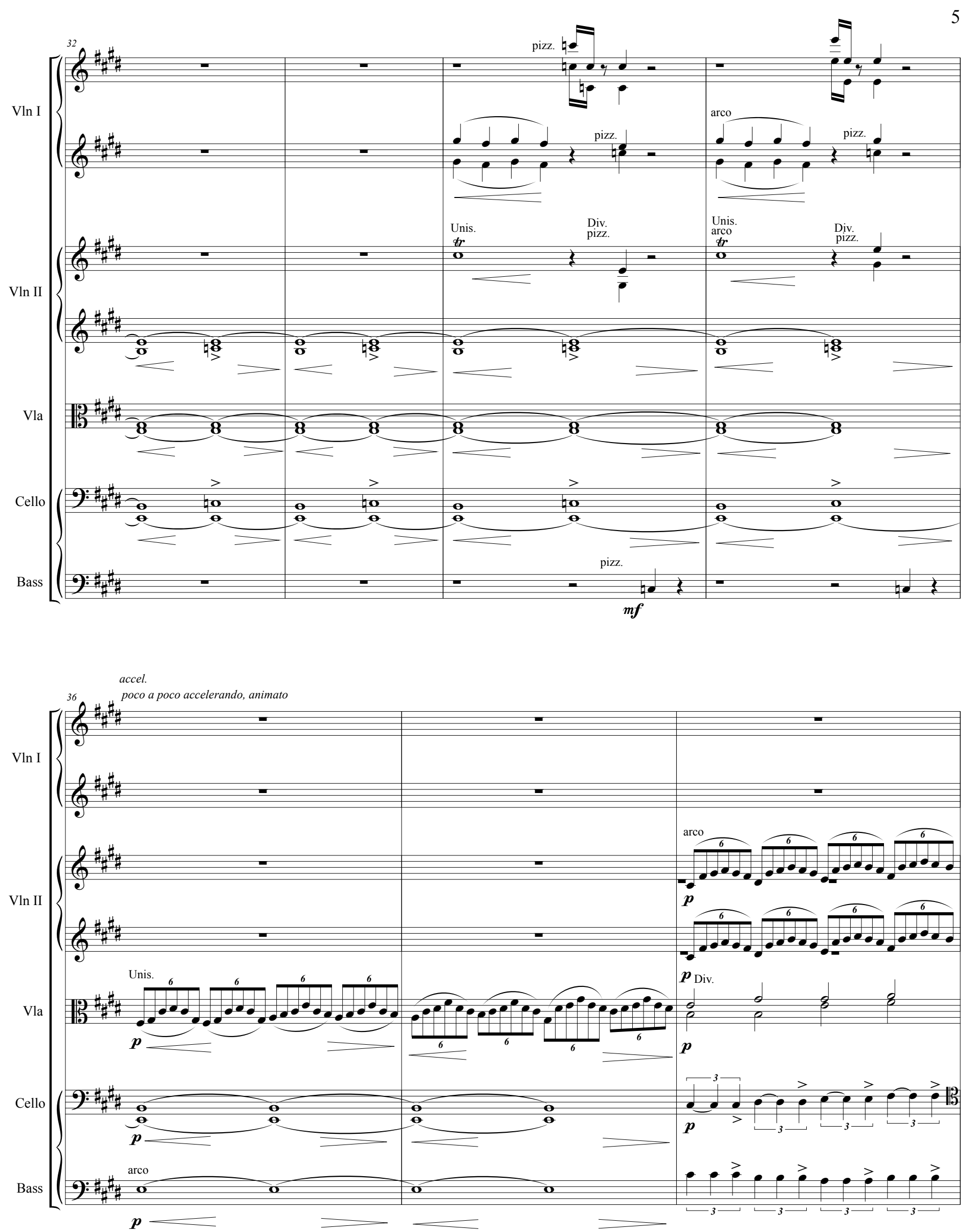

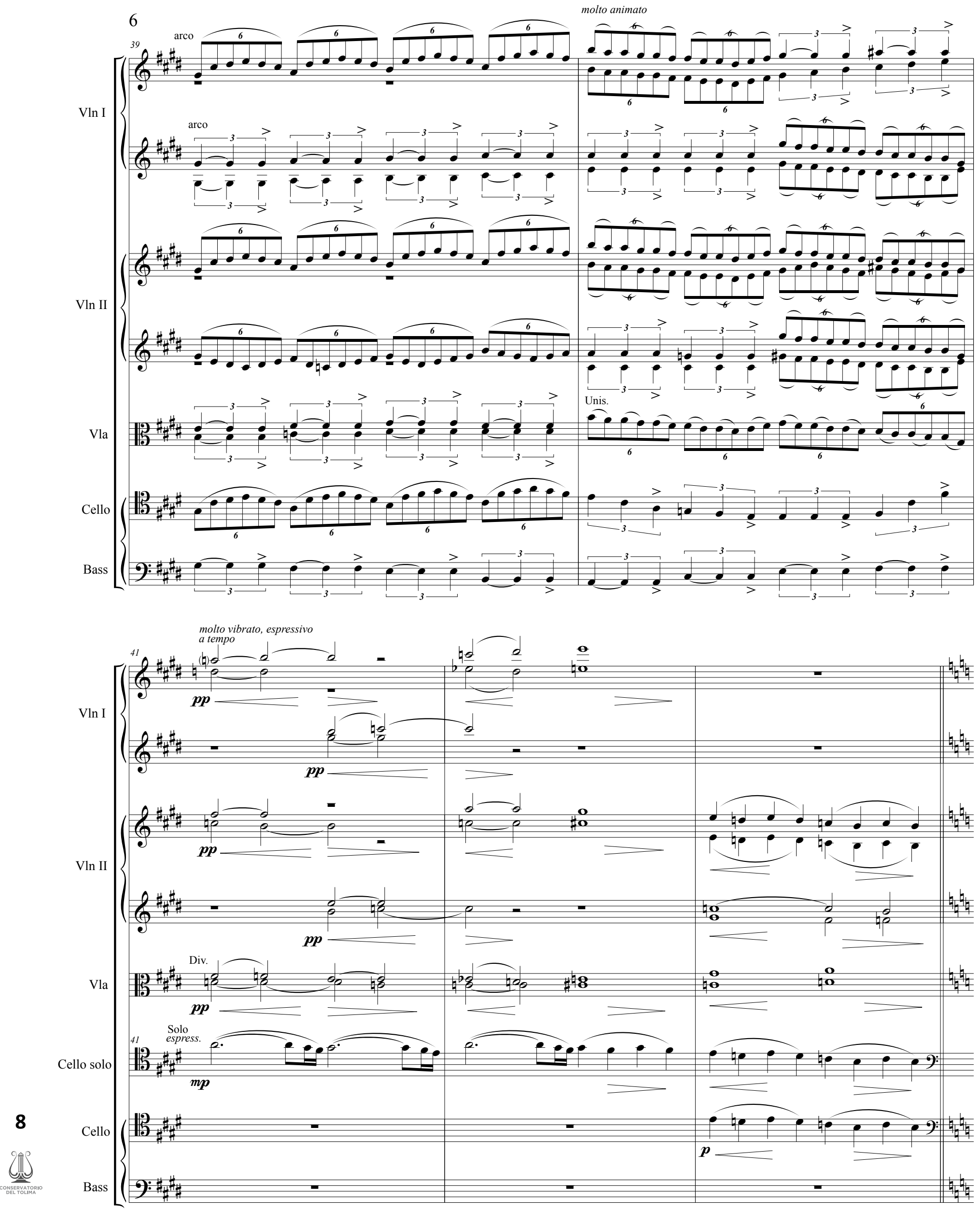

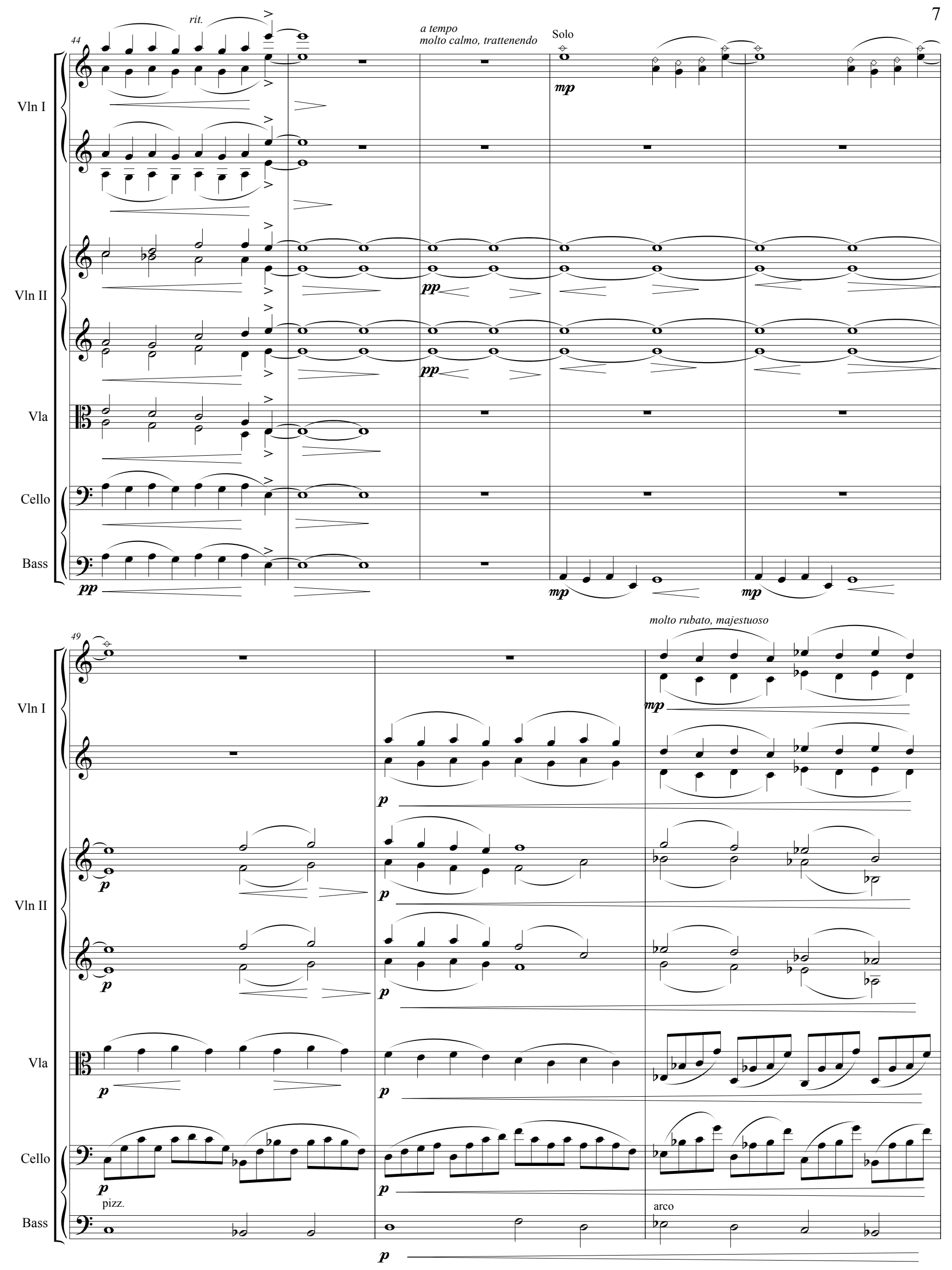

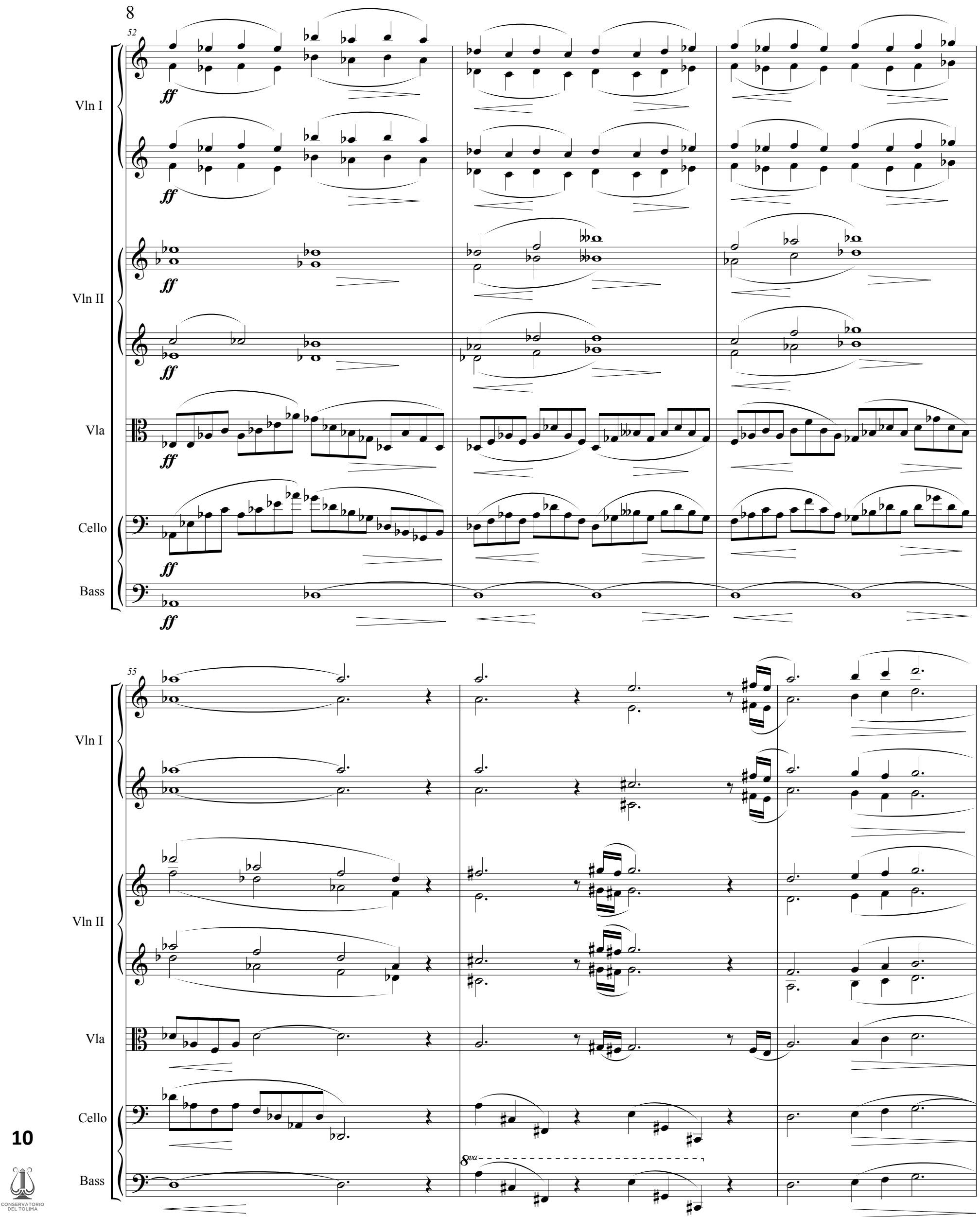


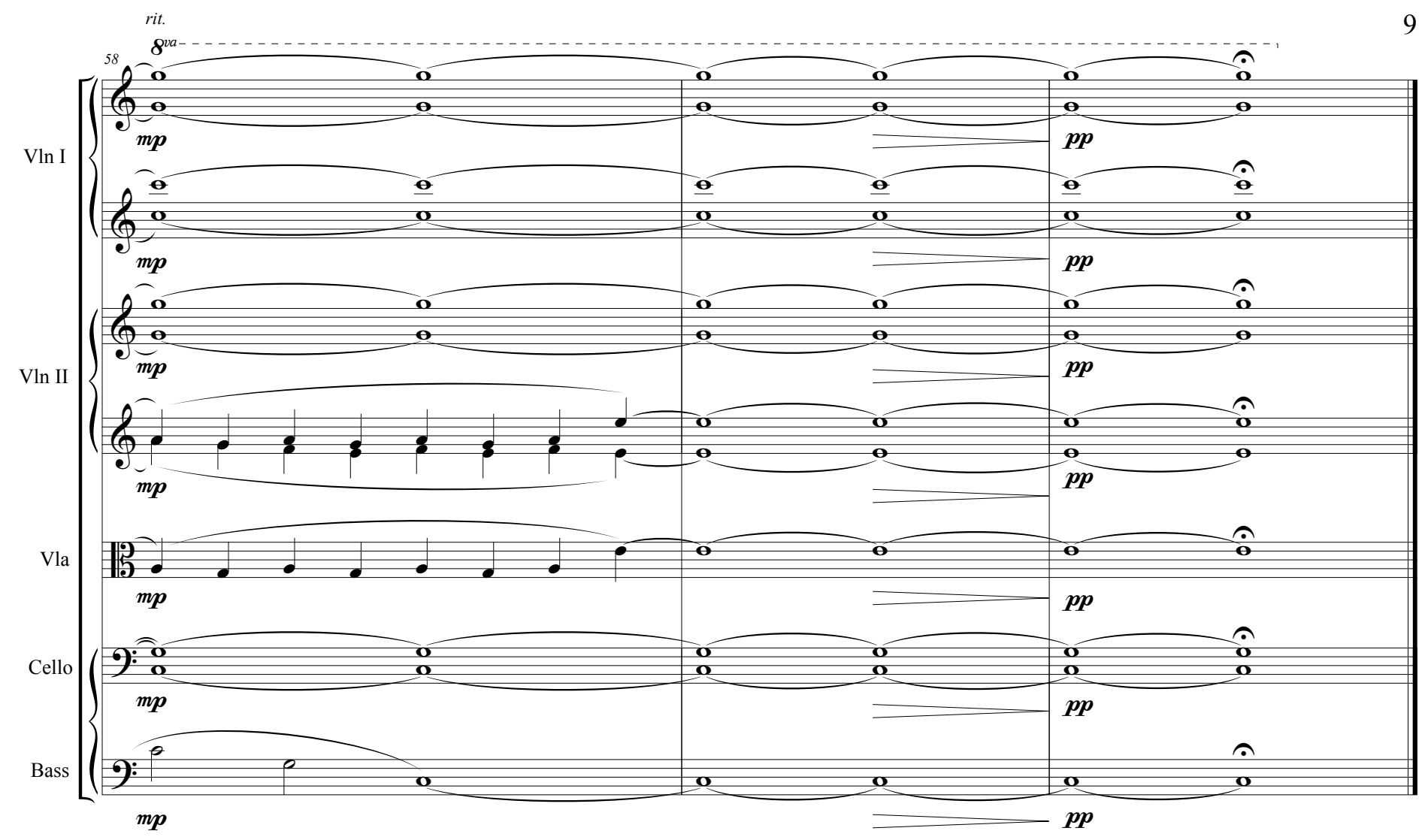




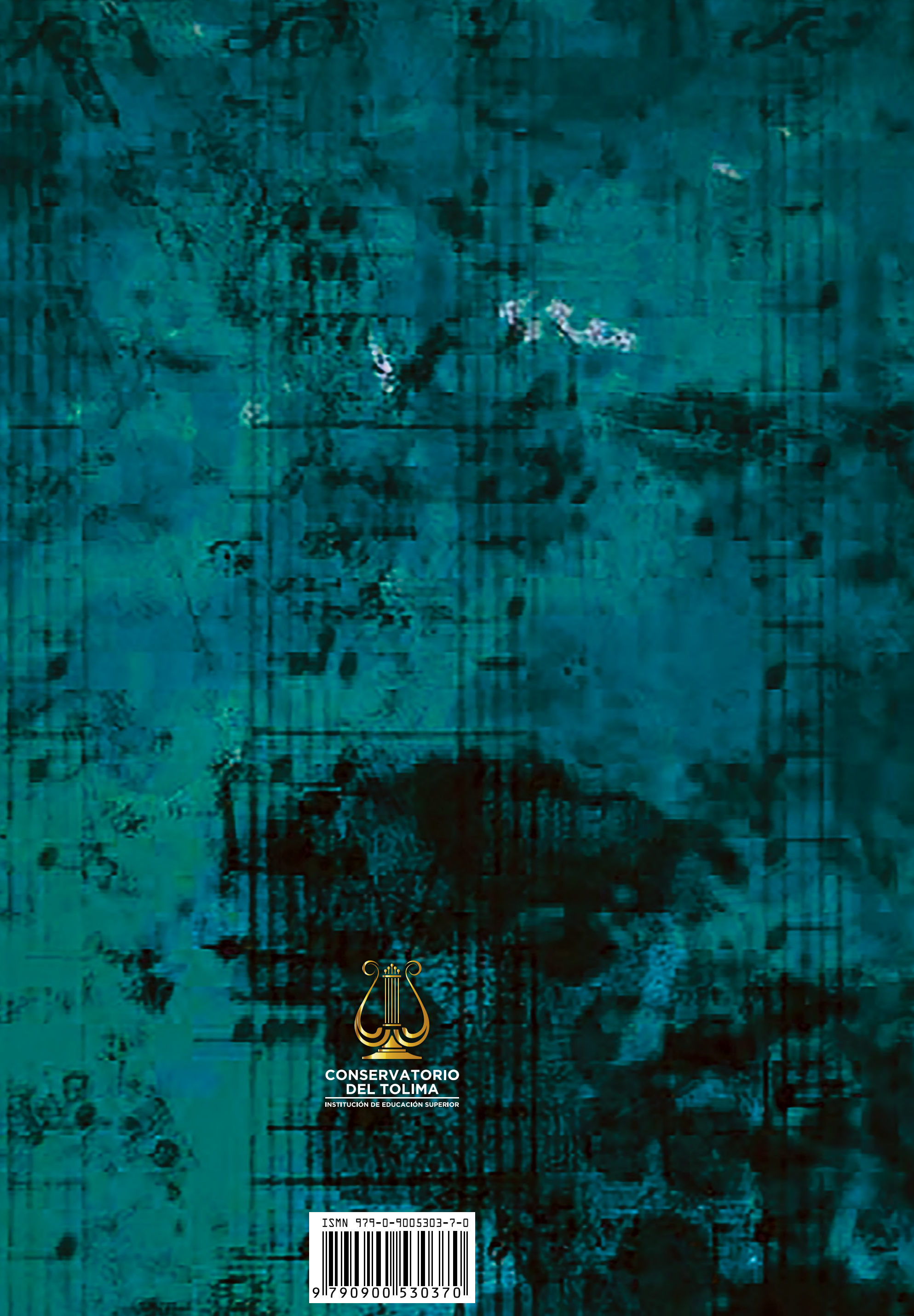

